\section{Comparison between molecular methods (PCR vs LAMP) to detect Candida albicans in bronchoalveolar lavage samples of suspected tuberculosis patients}

\author{
Meysam Goodarzi, ${ }^{1}$ \\ Mohammad Hassan Shahhosseiny, 2,3 \\ Mansour Bayat, ${ }^{1}$ \\ Seyed Jamal Hashemi, ${ }^{4}$ \\ Mohammad Ghahri ${ }^{5}$ \\ ${ }^{1}$ Department of Pathobiology, Faculty of \\ Veterinary Specialized Sciences, Science \\ and Research Branch, Islamic Azad \\ University, Tehran; ${ }^{2}$ Department of \\ Microbiology, Shahr-e-Qods Branch, \\ Islamic Azad University, Tehran; \\ ${ }^{3}$ Iranian Gene Fanavar Institute (IGF), \\ Tehran; ${ }^{4}$ Department of Medical \\ Parasitology and Mycology, Tehran \\ University of Medical Sciences, Tehran; \\ ${ }^{5}$ Department of Medical Mycology, \\ School of Basic Sciences, Imam Hossein \\ University, Tehran, Iran
}

\begin{abstract}
With the increase of patients suffering from immune deficiency infections also increased pulmonary fungi even in people with defective immune system can cause fatal and lethal candidiasis. The timely diagnosis of pulmonary candidiasis is one of the problems that has been detected. Polymerase chain reaction (PCR) test and Loop mediated isothermal amplification (LAMP) method optimized on the basis of $\alpha$ INT1 gene and then sensitivity and specificity were evaluated. LAMP is a novel nucleic acid amplification technique with high specificity and sensitivity which has been done under isothermal condition. Samples were the bronchoalveolar lavage suspected of tuberculosis (TB) reviews for TB disease negative have been reported. DNA extraction carried out by standard phenol/chloroform method on samples and PCR test and LAMP was done. PCR and LAMP testing was performed on samples and products of $441 \mathrm{bp}$ were amplified and observed with agarose gel electrophoresis. At the end of the LAMP reaction, SYBR Green was used for identifying negative and positive results. Among the 60 quantities sera, only 7 cases were PCR positive but 8 cases were LAMP positive. In comparison, between LAMP and PCR, the LAMP technique in spite of its simplicity, high sensitivity and specificity, could be an appropriate replacement for PCR.
\end{abstract}

\section{Introduction}

Candida albicans is a diploid fungus that grows both as yeast and filamentous cells and a causal agent of opportunistic infections in humans. ${ }^{1,2}$ The yeast Candida is an example of a highly successful opportunistic pathogen that takes advantage of host debilities and disorders to cause infections of a remarkably wide range of tissues. ${ }^{3}$ Candida albicans is the cause of many undesirable symptoms ranging from fatigue and weight gain, to joint pain and gas. ${ }^{4}$ Candidiasis may be divided into superficial (such as oral and vaginal thrush and chronic mucocutaneous candidiasis) and deep-seated (such as Candida due myocarditis and acute disseminated Candida septicaemia) and represent a major clinical problem. ${ }^{5}$ For several reasons (immunosuppressive treatments, long-term catheterization, use of broad spectrum antibiotics and longer survival of immunologically compromised individuals), Candida infections have increased dramatically over the last two decades. ${ }^{6}$ Sometimes the disease (pulmonary candidiasis) can unrecognized for a long time. ${ }^{7}$ TB is caused by the bacterium Mycobacterium tuberculosis. Although it can cause disease in any part of the body it normally enters the body though the lungs. ${ }^{8}$ TB is spread from an infectious person who is coughing, to another person through the air. Like the common cold, TB is spread through aerosolized droplets after infected people cough, sneeze or even speak. People nearby, if exposed long enough, may breathe in bacteria in the droplets and become infected. ${ }^{9} \mathrm{~TB}$ is one of the leading infectious diseases in the world and is responsible for more than 2 million deaths and 8 million new cases annually. ${ }^{10}$ The major difference between TB and candidiasis infections is that Possible candidiasis is Stay hidden. Thus it is particularly important to diagnose candidiasis as rapidly as possible. In addition, treatment varies according to the species of candidiasis, However At the first stages of revealing disease, detection methods based on antibody and biopsy are not recognizable. ${ }^{11}$ Molecular detection methods based on isolation and amplification of nucleic acid such as PCR, isothermal amplification, and hybridization are capable to recognize infection at early stages. ${ }^{12,13}$ Despite its advantages, each amplification method has it own problems. For example using PCR against expanded development and high accuracy because of needing to improved instrument like thermal cycler have not been distributed in all diagnostic center as a routine test up to now. ${ }^{14}$ loop-mediated isothermal amplification (LAMP)
Correspondence: Meysam Goodarzi, Department of Pathobiology, Faculty of Veterinary Specialized Sciences, Science and Research Branch, Islamic Azad University, Tehran, Iran.

Tel.: +98.912.1504398

E-mail: goodarzi2929@yahoo.com

Key words: Candida albicans, BAL Samples, PCR, LAMP.

Contributions: the authors contributed equally.

Conflict of interest: the authors declare no potential conflict of interest.

Received for publication: 9 July 2017.

Accepted for publication: 31 July 2017.

This work is licensed under a Creative Commons Attribution NonCommercial 4.0 License (CC BY-NC 4.0).

(C) Copyright M. Goodarzi et al., 2017 Licensee PAGEPress, Italy

Microbiology Research 2017; 8:7306

doi:10.4081/mr.2017.7306

Techniques is another method of isothermal amplification In which amplification $\mathrm{Be}$ done manner isothermal And therefore do not require a thermocycler, In addition, is the accuracy and sensitivity. ${ }^{15,16}$ This reaction is done without template DNA denaturation and whit using the polymerase with the ability to substitution in the chain, Also Is used of 6 specific primers that known as internal FIP (F1C, F2) and BIP, (B1C, B2) and external (F3, B3) (Special Loop LF, LB) primers that they have very high specificity. ${ }^{12,17}$ In this case there is no need to use by heat denaturation after amplification This means that all stages of amplification to detect is performed at a temperature Also when the reaction was accompanied with reverse transcription of RNA sequences can also be reproduced. ${ }^{14}$ So developed molecular methods provide for rapid detection feels more accurate than the traditional and old phenotypic methods and also for epidemiological studies and molecular analysis of an infectious agent is important for infection control.

\section{Materials and Methods}

Within a few months in one study of patients referred to a specialized TB laboratory in Tehran that showed specific symptoms of TB patients, 60 people who were randomly selected TB patients were negative. Sampling was done by a pulmonary 
specialist with Bronchoalveolar lavage (BAL) sample were prepared using standard. Samples were collected in sterile tubes and were transported to the laboratory as soon as possible.

\section{Preparation strains of Candida albi- cans and culturing methods}

First, lyophilized and standard strains of Candida albicans belonging to Iranian Industrial Bacteria and Fungi Collection (Persian Type Culture Collection, PTCC) were cultured at GYEP liquid medium. After the organism growth, $500 \mu \mathrm{L}$ of the liquid medium was removed and centrifuged at 12,000 rpm for $5 \mathrm{~min}$. The supernatant was discarded and resulting precipitation was deionized in $100 \mu \mathrm{L}$ of sterile double-distilled water and suspended; then, its DNA was extracted using phenolchloroform methods. ${ }^{18}$

\section{DNA extraction}

Extracting DNA from standard strain: Phenol-chloroform method was used for DNA extraction. ${ }^{18} 100 \mu \mathrm{L}$ of the cultured strain in the liquid medium was removed; then, at the first stage, $500 \mu \mathrm{L}$ of the lysis solution or buffer lysis (Proteinase $\mathrm{K}=250$ $\mu \mathrm{g} / \mathrm{mL}$, Tris- $\mathrm{Hcl}=50 \mathrm{Mm}, \mathrm{SDS}=10 \%$ ) was added. At the second stage, $10 \mu \mathrm{L}$ protease was added and shaken for $10 \mathrm{sec}$. At the third stage, it was put in a $65^{\circ}$ heater block for $20 \mathrm{~min}$. After removal of the solution inside the tube, phenol-chloroform solution was added and, after 10 times of inversion, it was centrifuged for $5 \mathrm{~min}$. Afterward, the tube was placed on ice for $30 \mathrm{~min}$. After removing from ice, the supernatant was transferred to a new tube and some isopropanol with the same volume of the solution was added to the tube. After 10 times of inversion, it was put in a $-20^{\circ} \mathrm{C}$ freezer for $10 \mathrm{~min}$. Once taken out of the freezer, it was centrifuged for $10 \mathrm{~min}$ at $12,000 \mathrm{rpm}$ and the supernatant was discarded; because isopropanol always causes DNA precipitation, the supernatant lacks any DNA. Afterwards, $1000 \mu \mathrm{L}$ of alcohol $70 \%$ was poured on it and, after 10 times of inversion, centrifuged for $10 \mathrm{~min}$ at $12000 \mathrm{rpm}$ (alcohol separates isopropanol from DNA). Finally, the supernatant was decanted (discarded), the test tube was placed in the $65^{\circ}$ heater block, and $100 \mu \mathrm{L}$ distilled water was added.

\section{Primer design}

PCR primers were designed for $\alpha$ INT1; the amplified region has 441 bp lengths. LAMP primers using Primer explorer V4 software was designed for gene alph-INT1. Specific primers of Candida albicans are as shown in Table 1.

\section{PCR method}

Every reaction contained $5 \mu \mathrm{L}$ DNA extracted from the sample or strain, $2.5 \mu \mathrm{L}$ $10 \times$ PCR Buffer, $0.5 \mu \mathrm{L}(0.2 \mu \mathrm{m})$ forward primer, $0.5 \mu \mathrm{L}(0.2 \mu \mathrm{m})$ reverse primer, 0.75 $\mu \mathrm{L} \mathrm{MgCl2}(50 \mathrm{mM}), 0.5 \mu \mathrm{L}$ dNTP $10 \mathrm{mM}$, $0.3 \mu \mathrm{L}$ Taq DNA polymerase $5 \mathrm{u} / \mu \mathrm{L}$ enzyme, and $15 \mu \mathrm{L}$ sterile double-distilled water in the final volume of $25 \mu \mathrm{L}$. Thermal protocol was as initial denaturation at $94^{\circ} \mathrm{C}$ for $30 \mathrm{sec}$, annealing temperature at $66^{\circ} \mathrm{C}$ for $30 \mathrm{sec}$, and polymerization (extension) stage at $72^{\circ} \mathrm{C}$ for $30 \mathrm{sec}$ in 33 cycles. Final polymerization was at $94^{\circ} \mathrm{C}$ for $5 \mathrm{~min} .{ }^{17}$ Thus, thermal profile was used for optimizing PCR tests for diagnosing Candida albicans.
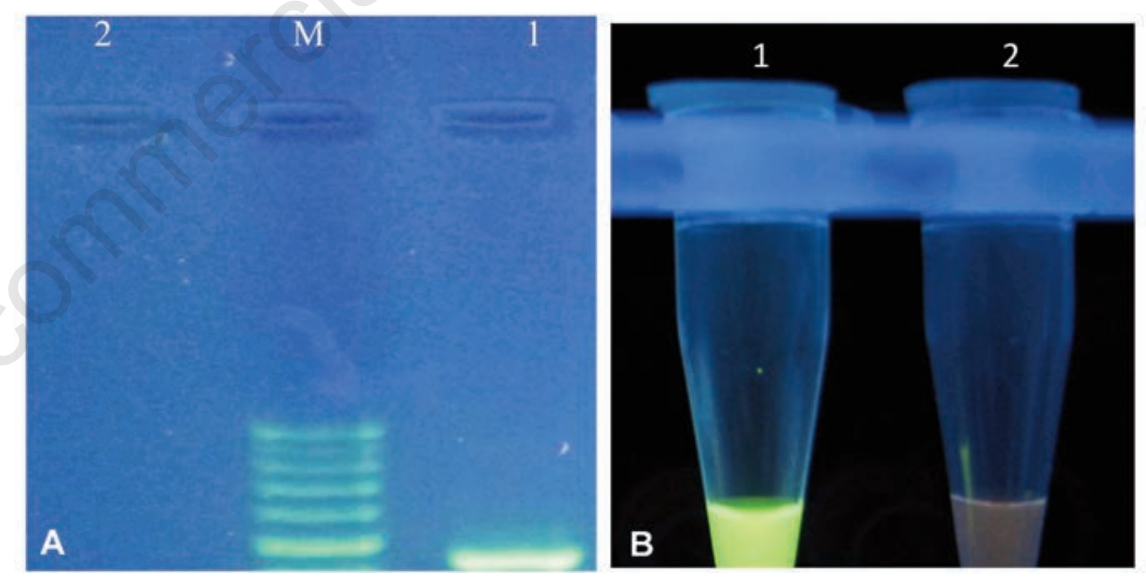

Figure 1. A) Optimized PCR test. M: size marker Frmentas 100bp DNA Ladder Line 1: amplified part of 441 bp Candida albicans, Line 2: Negative control. B) LAMP Optimized Test Tube 1: gene-specific amplification of Candida albicans Tube 2: negative control.

Table 1. Features of primers.

\begin{tabular}{|c|c|c|c|}
\hline Gene & Primer name & Sequence $\left(5^{\prime} \rightarrow 3^{\prime}\right)$ & PCR product size (bp) \\
\hline$\alpha$-INT1 & $\begin{array}{l}\text { F-C. } \alpha \text {-INT1 } \\
\text { R-C. } \alpha \text {-INT1 }\end{array}$ & $\begin{array}{l}\text { AGGCAACTCCTAAAGCGTCA } \\
\text { TGTTTTTCGAAGCTCTTGC }\end{array}$ & 441 \\
\hline$\alpha$-INT1 & $\begin{array}{l}\text { F3 } \\
\text { B3 } \\
\text { FIP } \\
\text { BIP }\end{array}$ & $\begin{array}{l}\text { CAATGGAAAGATCCTTCTCAA } \\
\text { TGTTATCTCTCTTGTGTGTCAT } \\
\text { AGGTTTCGTCGTATGAAGTGG } \\
\text { CAACGAAGTCAATCTGGAACCA }\end{array}$ & $\begin{array}{l}\text { CAAATGCT } \\
\text { CGCG }\end{array}$ \\
\hline
\end{tabular}


reactions. Different dilutions of fungal DNA from a million DNA copies (10-1 concentration) to one DNA copy (10-6 concentration) were prepared. This test is used to measure sensitivity of primers and indicates the delusions of fungus that can be identified by these primers

\section{Test specificity}

DNA from different microorganisms such as Cryptococcus neoformance, Fusarium spp., Fusarium Solani, Aspergillus parasiticus, Escherichia Coli (E.Coli), Hepatitis B virus (HBV), human DNA with the DNA of the fungus Candida albicans and specific primers for fungus placed in tube different and was performed LAMP test. Test specificity should be done separately the fungus Candida albicans.

\section{Results}

The PCR products were loaded on $1.5 \%$ agarose gel, the fragment's size obtained by using specific primers was 441 bp (Figure 1A). Optimized LAMP product with DNA extracted from standard strains The reaction by adding SYBR-Green were observed Positive tube bright green and negative tube very low orange colors (Figure 1B). LOD of PCR test with specific primers for Candida albicans could identify at least 100 copies of DNA related to each fungus of Candida albicans and LOD of LAMP test with specific primers for Candida albicans could identify at least 10 copies of DNA related to each fungus of Candida albicans (Figure 2). PCR and LAMP had high specificity showed no reaction to the other infectious agents except DNA Candida albicans (Figure 3).

\section{Discussion}

Opportunistic infections caused by yeasts in recent decades has been of great importance. ${ }^{19}$ This is due to the increasing incidence and prevalence of these infections in the community and nosocomial infections. Debilitating diseases such as AIDS, diabetes and cancer, and There is the use of catheters, organ transplants, cancer drugs, broad-spectrum antibiotics and Corticosteroids treatment of yeast infections is the subject of resolutions predisposing. ${ }^{20}$ Invasive candidiasis is a common and potentially fatal side effects caused by treatment, especially chemotherapy, cancer patients Candida species are the most common cause of fungal infections in humans, ${ }^{6,14}$ in patients with different respi- ratory infections. Diagnosis accurate and rapid identification can help of Candida to antifungal therapy because the molecular methods is not need culture and the diagnosis is possible in a few hours, in patients with different respiratory infections. Diagnosis accurate and rapid identification can help of Candida to antifungal therapy because the molecular methods is not need culture and the diagnosis is possible in a few hours, another advantage is high sensitivity of this methodse. ${ }^{21}$

LAMP New novel technique is one of the very simple gene amplification methods which were performed under isothermal condition. In contrary with its simplicity it has high specificity and sensitivity with obviating the need for using thermal cycler. ${ }^{22,23}$ At present time in all over the world grate studies have been developed to recognize infectious agent by LAMP technique. LAMP has verity characteristics and application besides diagnosis, including SNP typing and DNA quantification as realtime detection and particularly in development of g-POCT devices. ${ }^{24}$ This study primer the desired is designed from sequences encoding gene alph-INT1 Candida albicans. This gene is similar to vertebrates leukocytes eyntgren. ${ }^{25}$ This primer in terms of specificity with Candida spp, Cryptococcus neoformance, Fusarium spp, Fusarium solani, Aspergillus parasiticus, E.coli, HBV was tested; just alphaINT1 attached and did proliferation. This technique has a very high sensitivity and specificity in comparison with PCR and also against high sensitivity and specificity improved instruments was not required and the reaction was verified in a short time merely by using a simple heater. Among 60 cases with define viral load, 7 cases were PCR positive whether 8 cases were LAMP positive. Therefore because of significant

Table 2. The materials used in the LAMP test.

\begin{tabular}{|c|c|}
\hline 10X LAMP Buffer & $2.5 \mathrm{~mL}$ \\
\hline Betaine & $4 \mathrm{~mL}$ \\
\hline $\mathrm{dNTP}(10 \mathrm{mM})$ & $3 \mathrm{~mL}$ \\
\hline Primer Master Mix & $1 \mathrm{~mL}$ \\
\hline MgSo4 (100 mM) & $1.8 \mathrm{~mL}$ \\
\hline 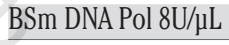 & $1 \mathrm{~mL}$ \\
\hline D.D.W & $6.7 \mathrm{~mL}$ \\
\hline Template DNA & $5 \mathrm{~mL}$ \\
\hline
\end{tabular}
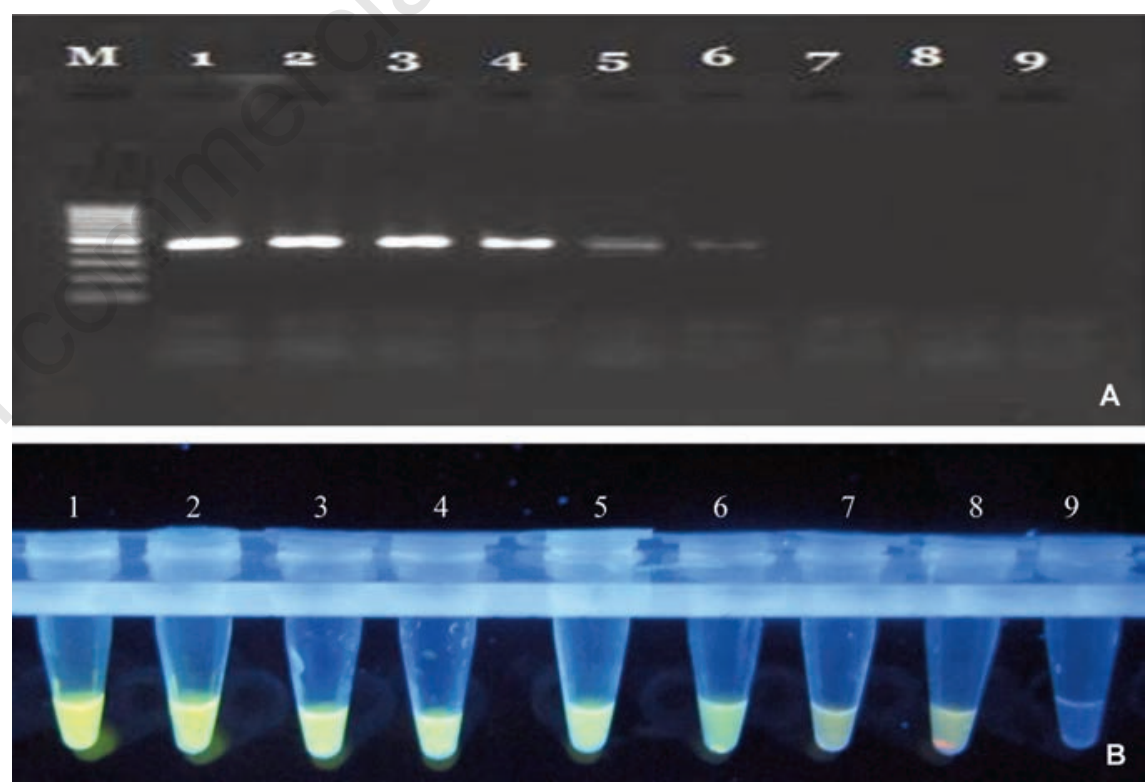

Figure 2. A) Results of LOD test. M: Size of $100 \mathrm{bp}$ DNA Ladder PLUS fermentas marker, Line 1: positive control, Line 2: Dilution of 10-1 equivalent to $1,000,000$ copies of DNA, Candida albicans, Line 3: dilution of 10-2 equivalent to 100,000 copies of DNA, Candida albicans, Line 4: dilution of 10-3 equivalent to 10,000 copies of DNA, Candida albicans, Line 5: dilution of 10-4 equivalent to 1000 copies of DNA, Candida albicans, Line 6: dilution of 10-5 equivalent to 100 copies of DNA, Candida albicans, Line7: dilution of 10-6 equivalent to 10 copies of DNA, Candida albicans, Line 8: dilution of 10-7 equivalent to 1 copy of DNA, Candida albicans, Line 9: negative control. B) Results of LOD test, Tube 1: positive control; Tube 2: 1,000,000, copies of DNA, Candida albicans; Tube 3: 100,000 copies of DNA, Candida albicans; Tube 4: 10,000 copies of DNA, Candida albicans; Tube 5: 1000 copies of DNA, Candida albicans; Tube 6: 100 copies of DNA, Candida albicans; Tube 7: 10 copies of DNA, Candida albicans; Tube 8: 1 copy of DN, Candida albicans; Tube 9: Negative control. 
LAMP sensitivity in this cases with similar condition, LAMP test was able to detect truly result which seems PCR test had not this property, so it can be mentioned that in this study yeast particles can be detected even thought in old samples with at least yeast load by using LAMP technique. Although improved instruments are not required in this technique, but it has grate sensitivity and accuracy that reaction can be done simply by applying just a dry-plate .By adding $0.1 \%$ SYBR Green and observing under U.V light the result could be obtained, so needing to post amplification processes like as electrophoresis were obviate. Given that the departments of molecular diagnostic have higher speed and accuracy toward tests based on phenotype diagnostic tests based on phenotype, other researchers have shown priority this method over the frequently asked methods and also in clinical laboratories Replace methods are frequently asked methods and used routinely. So it can be stated With the help of this techniques may be provided. Molecular methods have helped to rapid and accurate detect of Candida albicans Rapid and available detection Candida albicans and timely treatment of patients be prevented from rising costs patients the results of this study are help to remove disease and avoid increasing costs to patients for early diagnosis. Optimistically It is no far that in near future by using LAMP technique, Candida detection possibility without administering improved instrument with significant sensitivity and specificity and also cost saving will be available in all diagnostic centers.
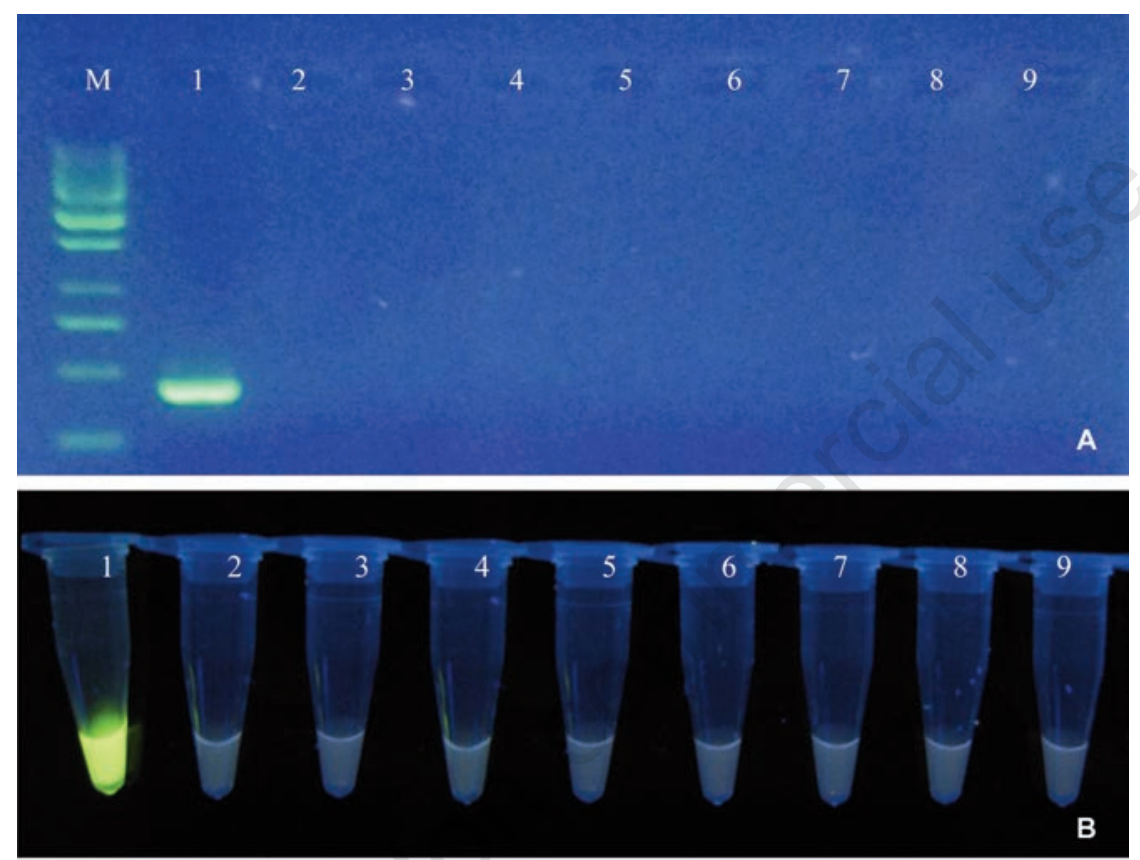

\section{References}

1. Ryan KJ, Ray CG, eds. Sherris medical microbiology. 4th ed. New York: McGraw Hill; 2003.

2. Enfert C, Hube B, eds. Candida: comparative and functional genomics. Wymondham: Caister Academic Press; 2007.

3. Edwards JE. Invasive candida infections: evolution of a fungal pathogen. $\mathrm{N}$ Engl J Med 1991;324:1060-2.

4. Mannarelli BM, Kurtzman CP. Rapid identification of Candida albicans and other human pathogenic yeasts by using short oligonucleotides in a PCR. J Clin Microbiol 1998;36:1634-41.

5. Karahan ZC, Guriz H, Agirbasli H, et al. Genotype distribution of Candida albicans isolates by $25 \mathrm{~S}$ intron analysis with regard to invasiveness. Mycoses 2004;47:465-9.

6. Al-Abeid HM, Abu-Elteen KH, Elkarmi AZ, Hamad MA. Isolation and characterization of Candida spp. in Jordanian cancer patients: prevalence, pathogenic determinants, and antifungal sensitivity. Jpn J Infect Dis 2004;57:279-84.

7. Fair E, Hopewell P, Pai M. International standards for tuberculosis care: revisiting the cornerstone of tuberculosis care and control. Expert Rev Anti Infect Ther 2007;5:61-5.

8. Oh YW, Effmann EL, Godwin JD. Pulmonary infections in immunocompromised hosts: the importance of correlating the conventional radiologic appearance with the clinical setting. Radiology 2000;217:647-56.

Figure 3. A) Specificity test, M: size marker Frmentas 1Kb DNA Ladder, Line 1: DNA of Candida albicans, Line 2 to 8: DNA of Cryptococcus neoformance, Fusarium spp., Fusarium solani, Aspergillus parasiticus, E.coli, Hepatitis B virus; Line 9: Negative control. B) Tube1: DNA of Candida albicans; Tube 2 to 8 and: DNA Cryptococcus neoformance, Fusarium spp, Fusarium solani, Aspergillus parasiticus, Aspergillus flavus, E.coli, Hepatitis B virus; Tube 9: negative control. C) Primers designed reacted with Candida dubliniensis but no reaction with other Candida species Tube 1: DNA of Candida albicans; Tube 2: DNA Candida dubliniensis; Tube 3, 4, 5: Candida parapsilosis, Candida tropicalis, Candida glabrata; Tube 6: negative control.

9. World Health Organization. Global tuberculosis control. Geneva: WHO/CDS/TB; 2002. pp 295.

10. Dye C, Scheele S, Dolin P, et al. Global burden of tuberculosis: estimated inci- 
dence, prevalence, and mortality by country. JAMA 1999;282:677-86.

11. Dienstag JL. Hepatitis B virus infection. N Engl J Med 2008;359:1486-500.

12. Vernet $G$. Molecular diagnostics in virology. J Clin Virol 2004;31:239-47.

13. Shahhosseiny MH, Tehrani R. Polymerase chain reaction (PCR) 165p. Islamic Azad University. 2005. pp. 4568.

14. Zhang D, Zhang W, Li X, Konomi Y. Detection of rare DNA targets by isothermal ramification amplification. Gene 2001;274:209-16.

15. Anaissie EJ, McGinnnis MR, Pfaller MA. Clinical mycology. 1st ed. Churchill \& Livingstone; 2003. pp 31613.

16. Sarosi GA, Davies SF. Fungal disease of the lung. 3rd ed. New York: Lippincott Williams and Wilkins; 2000.
17. Shahhosseiny MH. Basic molecular diagnosis. Islamic Azad University; 2005. pp 12-35.

18. Sambrook J, Russell DW. Purification of nucleic acids by extraction with phenol: chloroform. Cold Spring Harbor Protocols, 2006, pdb.prot4455.

19. Pfaller MA. Epidemiology of candidiasis. 1995;30:329-38.

20. Perlroth J, Choi B, Spellberg B. Nosocomial fungal infections epidemiology, diagnosis, and treatment. Med Mycol 2007;45:321-46.

21. Miyakawa Y, Mabuchi T, Kagaya K, Fukazawa Y. Isolation and characterization of a species-specific DNA fragment for detection of Candida albicans by polymerase chain reaction. J Clin Microbiol 1992;30:894-900.

22. Mori Y, Notomi T. Loop-mediated isothermal amplification (LAMP): a rapid, accurate, and cost-effective diagnostic method for infectious diseases. J Infect Chemother 2009;15:62-9.

23. Notomi T, Okayama H, Masubuchi H, et al. Loop-mediated isothermal amplification of DNA. Nucleic Acids Res 2000;28:63.

24. Parida M, Sannarangaiah S, Kumar Dash P, et al. Loop mediated isothermal amplification (LAMP): a new generation of innovative gene amplification technique; perspectives in clinical diagnosis of infectious diseases. Rev Med Virol 2008;18:407-21.

25. Marcilla A, Monteagudo C, Mormeneo S, Sentandreu R. Monoclonal antibody 3H8: a useful tool in the diagnosis of candidiasis. Microbiology 1999;145: 695-701. 